\title{
STUDYING THE DEFORMATION RESISTANCE OF EP679 MARAGING STEEL
}

\author{
S. V. Gladkovsky, A. I. Potapov, S. V. Lepikhin* \\ Institute of Engineering Science, Ural Branch of the Russian Academy of Sciences, 34 Komsomolskaya st., \\ Ekaterinburg, Russian Federation \\ *Corresponding author. E-mail: 1sv@imach.uran.ru; address for correspondence: ul. Komsomolskaya, 34, 620049, \\ Ekaterinburg, Russian Federation. Tel.: +7 (343) 362-34-48; fax: +7 (343) 374-53-30
}

The resistance of high-strength maraging steel EP679 to plastic deformation $\sigma_{\mathrm{s}}$ is studied as dependent on the amount of strain, strain rate and deformation temperature, as well as on heattreatment conditions. Quantitative evaluation is obtained and regularities are found in the change of $\sigma_{\mathrm{s}}$ values depending on the studied factors, with the structural evolution of steel under heating and cooling taken into account. A positive effect of preheating up to $920{ }^{\circ} \mathrm{C}$ and subsequent cooling to the test temperature on the decrease in the value of $\sigma_{s}$ during subsequent deformation at temperatures ranging between 20 and $900{ }^{\circ} \mathrm{C}$ is shown.

Keywords: maraging steel, deformation resistance, plastometric tests, structure, phase transformations.

DOI: $10.17804 / 2410-9908.2015 .4 .018-028$

\section{References}

1. Perkas M.D., Kardonsky V.M. Vysokoprochnye martensitno-stareyushchie stali [Highstrength maraging steels]. Moscow, Metallurgiya Publ., 1970, 224 p. (In Russian).

2. Georgiev M.N., Simonov Yu.N. Treshchinostoykost zhelezouglerodistykh splavov [Crack resistance of iron-carbon alloys]. Perm, Izdatelstvo Permskogo natsionalnogo issledovatelskogo politekhnicheskogo universiteta Publ., 2013, 419 p. (In Russian).

3. Efros B.M., Konakova I.P., Gladkovsky S.V., Tyutenko V.S., Loladze L.V., Zaika T.P., Varyukhin V.N. Effect of the conditions of thermoplastic treatment on the deformation resistance, mechanical properties and crack resistance of cobalt-free maraging steels. Fizika i tekhnika vysokikh davleny, 1997, vol. 7, no. 4, pp. 5-23. (In Russian).

4. Veksler Yu.G., Zvigintsev N.V., Konakova I.P., Belova G.V., Suntsev G.N. Deformability of steel $03 \mathrm{Kh} 11 \mathrm{~N} 10 \mathrm{M} 2 \mathrm{~T}$ at temperatures ranging between 20 and $1100{ }^{\circ} \mathrm{C}$. Izvestiya vuzov. Chernaya metalluriya, 1986, no. 8, pp. 74-78. (In Russian).

5. Potapov A.I., Mazunin V.P., Dvoynikov D.A., Kokovikhin E.A. Methods for studying deformation resistance on a plastometric complex. Zavodskaya laboratoriya. Diagnostika materialov, 2010, vol. 76, no. 9, pp. 59-63. (In Russian).

6. Terentiev V.V., Bunin I.Zh., Zagreev P.V. Effect of the aging temperature on the complex of mechanical properties of maraging steel. Materialovedenie, 1998, no. 1, pp. 40-49. (In Russian).

7. Tarasenko L.V., Zvigintsev N.V., Titov V.I., Khadyev M.S. Phase transformations in steel 00Kh11M2T...T1 under long-term aging. FMM, 1987, vol. 63, iss. 4, no. 6, pp. 768-773. (In Russian).

8. Shaposhnikov N.G., Mogutnov B.M., Zvigintsev N.V., Khadyev M.S. Termodinamicheskiy analiz fazovykh ravnovesiy $\mathrm{v}$ martensitnostareyushchikh stalyakh. In: Heat treatment, structure and properties of metals. Interuniv. coll., Sverdlovsk, UPI Publ., 1985, iss. 10, pp. 3-9. (In Russian).

9. Georgiev M.N., Simonov Yu.N. Treshchinostoykost zhelezouglerodistykh splavov [Crack resistance of iron-carbon alloys]. Perm, PNRPU Publ., 2013, 419 p. (In Russian).

10. Vylezhnev V.P., Sukhikh A.A., Bragin V.G., Kokovyakina S.A. Mechanical properties of grade N18K9M5T maraging steel containing retained and reversed austenite. The Physics of Metals and Metallography, 1993, vol. 75, no. 4, pp. 157-165. 
11. Gladkovsky S.V., Zvigintsev N.V., Kruglov A.A., Doroshkevich T.A., Fazliakhmetov R.S., Yurovskikh V.V. Effect of structural transformations on the mechanical properties and crack resistance of cobalt-free maraging steels. FMM, 1990, iss. 2, pp. 106-113. (In Russian). 
Подана в журнал: 03.06.2015

УДК 669.15-194.55:621.78

DOI: $10.17804 / 2410-9908.2015 .4 .018-028$

\title{
ИССЛЕДОВАНИЕ СОПРОТИВЛЕНИЯ ДЕФОРМАЦИИ МАРТЕНСИТНО- СТАРЕЮЩЕЙ СТАЛИ ЭП679
}

\author{
С.В. Гладковский, А.И. Потапов, С.В. Лепихин* \\ Федеральное бюджетное учреждение науки Институт машиноведения Уральского отделения Российской \\ академии наук ул. Комсомольская, 34, Екатеринбург, Российская Федерация \\ *Ответственный автор. Электронная почта: 1sv@imach.uran.ru; адрес для переписки: ул. Комсомольская, 34, \\ Екатеринбург, Российская Федерация. Телефон: +7 (343) 362-34-48, факс: +7 (343) 374-53-30
}

Проведено исследование сопротивления пластической деформации $\sigma_{\mathrm{s}}$ высокопрочной мартенситно-стареющей стали ЭП679 в зависимости от степени, скорости, температуры деформации и режима термической обработки. Получена количественная оценка и установлены закономерности изменения величины $\sigma_{\mathrm{s}}$ в зависимости от исследуемых факторов, с учетом структурных изменений в стали при нагреве и охлаждении. Показано положительное влияние предварительного нагрева до $920{ }^{\circ} \mathrm{C}$ и последующего охлаждения до температуры испытания на снижение величины $\sigma_{\mathrm{s}}$ при последующей деформации в интервале температур от 20 до $900{ }^{\circ} \mathrm{C}$.

Ключевые слова: мартенсито-стареющяая сталь, сопротивление деформации, пластометрические испытания, структура, фазовые превращения.

\section{1. Введение}

С конца 50-х годов прошлого столетия получили широкое распространение в различных областях технического применения как новый класс конструкционных материалов высокопрочные мартенситно-стареющие стали (MCC) на Fe-Ni-Co-Mo, Fe-NiMo-Ti и Fe-Cr-Ni-Mo основах [1, 2]. В настоящее время эти стали применяются в авиакосмической технике и специальном машиностроении для производства деталей и изделий ответственного назначения, работающих в сложных температурно-силовых условиях нагружения. Интерес к процессам обработки МСС давлением и, в частности, к изучению их реологических свойств в широком температурном диапазоне [3, 4] связан с оптимизацией режимов термомеханической обработки и возможностью получения в данных материалах методами интенсивной пластической деформации ультрамелкозернистых и нанокристаллических структур. Информация о сопротивлении деформации необходима для расчета энергосиловых параметров процессов обработки металлов давлением, выбора материала и технологии изготовления деформирующего инструмента, а в ряде случаев - для оценки возможности практической реализации процесса обработки давлением в исследовательской или производственной практике.

\section{2. Материал и методика}

В статье представлены результаты исследования сопротивления деформации $\sigma_{\mathrm{s}}$ мартенситно-стареющей стали ЭП679 при температурах холодной, теплой и горячей деформации (в интервале от 20 до $1100{ }^{\circ} \mathrm{C}$ ). Исследование проведено на пластометрическом комплексе ЦКП «Пластометрия» ИМАШ УрО РАН по методике, подробно изложенной в работе [5]. Сопротивление деформации определяли путем осадки цилиндрических образцов диаметром $D_{o}=10 \pm 0,1$ мм и высотой $H_{o}=14 \pm 0,1$ мм, вырезанных и изготовленных из поковки сечением 70х70 мм. 
Степень деформации оценивали величиной истинной деформации $e=\ln H_{o} / H_{\kappa}$, где $H_{\kappa}$ - высота осаженного образца. Сопротивление деформации определялось по формуле $\sigma_{\mathrm{s}}=\mathrm{P} / \mathrm{F}$, где $\mathrm{P}$ - измеренная сила (кH); F - площадь поперечного сечения образца в данный момент времени, мм ${ }^{2}$. Скорость деформации при осадке определяли как $\xi=v / \mathrm{h}$, где $v-$ скорость перемещения ползуна (мм/c); h - высота образца в текущий момент, мм. Осадку образцов осуществляли на $e \approx 0,65-1,0$ (50 - $65 \%$ от исходной высоты).

Проведенный химический анализ на оптическом эмиссионном спектрометре SPECTROMAXх позволил определить содержание основных химических элементов и примесей в изученной стали (табл. 1).

Таблица 1 - Химический состав исследуемой стали

\begin{tabular}{|c|c|c|c|c|c|c|c|c|c|c|}
\hline Сталь & \multicolumn{10}{|c|}{ Химический состав, масс. \% } \\
\hline \multirow{2}{*}{$Э П 679$} & $\mathrm{Fe}$ & $\mathrm{C}$ & $\mathrm{Si}$ & $\mathrm{Mn}$ & $\mathrm{Cr}$ & $\mathrm{Ni}$ & $\mathrm{Mo}$ & $\mathrm{Ti}$ & $\mathrm{S}$ & $\mathrm{P}$ \\
\cline { 2 - 11 } & осн. & 0,04 & 0,15 & 0,058 & 11,24 & 8,94 & 2,04 & 1,01 & 0,007 & 0,016 \\
\hline
\end{tabular}

Заготовки поперечным сечением $14 \times 14$ мм перед вырезкой образцов были подвергнуты закалке в воду после нагрева до $920{ }^{\circ} \mathrm{C}$ с выдержкой 60 мин. Твердость металла закаленных образцов находилась в пределах 26 - 30 HRC. В процессе испытаний варьировали: $\left.1100^{\circ} \mathrm{C}\right)$

- температуру испытаний $t_{\text {исп }}(20,200,300,400,500,600,700,800,900,1000$ и

- $\quad$ скорость деформации при осадке $\xi\left(1,10\right.$ и $\left.50 \mathrm{c}^{-1}\right)$;

- режим нагрева под испытание (образцы или подвергали «прямому» нагреву до

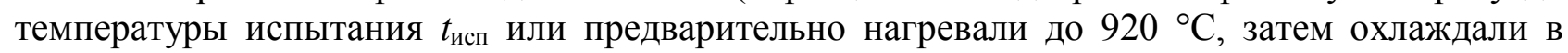
печи до $t_{\text {исп }}$ со скоростью $\sim 150{ }^{\circ} \mathrm{C} /$ ч и выдерживали при этой температуре $15-20$ мин);

- $\quad$ режим термообработки (серию образцов испытывали при $20^{\circ} \mathrm{C}$ после упомянутой выше закалки, вторую - после закалки и старения при температурах 400, 500, 600 и $700{ }^{\circ} \mathrm{C}$ в течение 3 ч).

Отметим, что после старения твердость образцов вследствие выделения в структуре интерметаллидов повышалась до величин, указанных в табл. 2. Наибольший уровень твердости имел место после старения при $500{ }^{\circ} \mathrm{C}$.

Таблица 2 - Зависимость твердости от температуры старения

\begin{tabular}{|c|c|c|c|c|}
\hline $\begin{array}{c}\text { Температура } \\
\text { старения, }{ }^{\circ} \mathrm{C}\end{array}$ & 400 & 500 & 600 & 700 \\
\hline Твердость, HRC & $36-39$ & $46-49$ & $37-39$ & $29-33$ \\
\hline
\end{tabular}

Образцы перед нагревом помещали в круглый металлический контейнер между бойками из твердого сплава. Пространство между стенками контейнера и образцом заполняли каолиновой ватой для исключения его охлаждения при выдаче из печи и осадке. Нагрев в электрической печи вели путем посадки образцов в разогретую до заданной температуры печь и выдержки в течение $60-30$ мин в зависимости от температуры нагрева (с увеличением температуры нагрева выдержка сокращалась). Для минимизации трения использовали смазки, состав которых определялся температурой нагрева под осадку.

\section{3. Результаты и обсуждение}

Известно [2, 6-9], что сталь данного состава после закалки имеет структуру дислокационного реечного мартенсита и содержит до $10 \%$ остаточного аустенита и незначительную долю первичных карбонитридов. При нагреве до $400{ }^{\circ} \mathrm{C}$ заметных 
изменений тонкой структуры не наблюдается. Однако по данным [7] в интервале температур 200 - $450{ }^{\circ} \mathrm{C}$ происходит расслоение твердого раствора по хрому и образуются предвыделения типа зон Гинье-Престона сферической формы. Обобщая результаты, полученные разными авторами на основе резистометрических, калориметрических и электронно-микроскопических исследований, можно установить последовательность фазовых и структурных превращений, развивающихся в МСС типа 03Х11Н10М2Т (ЭП678 и ЭП679) при нагреве выше температуры $400{ }^{\circ} \mathrm{C}$ :

- образование метастабильной фазы $\beta-\mathrm{Ni}_{3} \mathrm{Ti}\left(400-480{ }^{\circ} \mathrm{C}\right)$;

- $\quad$ образование стабильной фазы $\eta-\mathrm{Ni}_{3} \mathrm{Ti}\left(480-560{ }^{\circ} \mathrm{C}\right)$;

- нагрев до температур в интервале 590 - $680{ }^{\circ} \mathrm{C}$ и последующее охлаждение приводят к появлению в структуре ревертированного аустенита, располагающегося в виде тонких прослоек вдоль мартенситных кристаллов или участков неправильной формы;

- $\quad$ образование в аустените частиц фазы Лавеса $\lambda-\mathrm{Fe}_{2}(\mathrm{Ti}, \mathrm{Mo})$ и $\chi-(\mathrm{Fe}, \mathrm{Ni})_{38} \mathrm{Cr}_{10} \mathrm{Mo}_{4} \mathrm{Ti}_{6}$ $\left(600-850^{\circ} \mathrm{C}\right)$;

- $\quad$ измельчение аустенитного зерна $-850{ }^{\circ} \mathrm{C}$;

- увеличение размера аустенитного зерна и растворение фазы Лавеса $-900{ }^{\circ} \mathrm{C}$;

- $\quad$ аномальный рост аустенитного зерна $-1050^{\circ} \mathrm{C}$.

Температуры 850 и $1050{ }^{\circ} \mathrm{C}$ для данной стали можно считать температурами начала процесса рекристаллизации и собирательной рекристаллизации соответственно. Основной упрочняющей фазой в сталях типа $03 \mathrm{X} 11 \mathrm{H} 10 \mathrm{M} 2 \mathrm{~T}$ является интерметаллидная фаза $\mathrm{Ni}_{3} \mathrm{Ti} \mathrm{c}$ ГПУ решеткой. Частицы $\mathrm{Ni}_{3} \mathrm{Ti}$ равномерно распределены в матрице внутри кристаллов-реек и на стадии упрочняющего старения имеют игольчатую форму. В зависимости от температуры старения диаметр интерметаллидных частиц $\mathrm{Ni}_{3} \mathrm{Ti}$ меняется в пределах $\approx 30-$ 70 нм, а длина $\approx 100-200$ нм. После старения в межкритическом интервале $600-650{ }^{\circ} \mathrm{C}$ в результате развития обратного $\alpha \rightarrow \gamma$-превращения появляется так называемый ревертированный аустенит, который частично сохраняется в структуре стали при охлаждении до комнатной температуры и располагается преимущественно в виде тонких прослоек по границам мартенситных кристаллов. Следует отметить, что после длительных выдержек (сотни и тысячи часов) ревертированный аустенит может образовываться и при более низких температурах порядка $500{ }^{\circ} \mathrm{C}$. Методом электронной микроскопии установлено [6], что упрочняющая фаза $\mathrm{Ni}_{3} \mathrm{Ti}$ присутствует только в мартенсите, а при образовании аустенита она растворяется. Фаза $\mathrm{Ni}_{3} \mathrm{Ti}$ является термодинамически устойчивой для сплавов данной группы в интервале температур 400 - $600{ }^{\circ} \mathrm{C}$. В аустените при повышенных температурах старения образуется фаза Лавеса $\mathrm{Fe}_{2}(\mathrm{Ti}$, Mo). Образовавшиеся частицы фиксируются при быстром охлаждении как в мартенсите, так и в остаточном аустените. При повторном «новом» старении наследованные мартенситом фазы Лавеса заменяются более устойчивыми частицами фазы $\mathrm{Ni}_{3} \mathrm{Ti}$. Выделения фаз Лавеса, находящиеся в областях остаточного аустенита, не исчезают. А так как участки остаточного аустенита располагаются, как правило, по границам мартенситных кристаллов, то там же расположены частицы фаз Лавеса. По данным $[10,11]$, содержащийся в структуре МСС остаточный и ревертированный аустенит при пластической деформации может превращаться в мартенсит деформации.

Экспериментально полученные в настоящей работе кривые упрочнения закаленной стали ЭП679 при скорости деформации $\xi=1 \mathrm{c}^{-1}$ после прямого нагрева до $t_{\text {исп и }}$ предварительного нагрева до $920^{\circ} \mathrm{C}$ с последующим охлаждением до $t_{\text {исп }}$ представлены на рис. 1. Ход кривых упрочнения и величина сопротивления деформации в том и другом случае заметно различаются.

Из анализа полученных данных следует, что при прямом нагреве сопротивление деформации стали незначительно снижается с повышением температуры испытания с 20 до $400{ }^{\circ} \mathrm{C}$, оставаясь при этом довольно высоким (в пределах 1050 - 1200 МПа). Существенное 
снижение $\sigma_{\mathrm{s}}$ имеет место при температурах испытания $600-700{ }^{\circ} \mathrm{C}$ и выше, а также при переходе к горячей деформации $\left(t_{\text {исп }}=900-1100{ }^{\circ} \mathrm{C}\right)$.

При температуре $500{ }^{\circ} \mathrm{C}$ наблюдается резкое повышение $\sigma_{\mathrm{s}}$ до уровня, близкого к полученному в процессе испытания образцов при комнатной температуре. Аномальное поведение металла при осадке после прямого нагрева до $500{ }^{\circ} \mathrm{C}$, т.е. высокий уровень $\sigma_{\mathrm{s}}$, особенно на начальном этапе деформации, обусловлен, по-видимому, протеканием процессов дисперсионного твердения (старения) металла при нагреве и выдержке образцов (40 мин) при этой температуре.

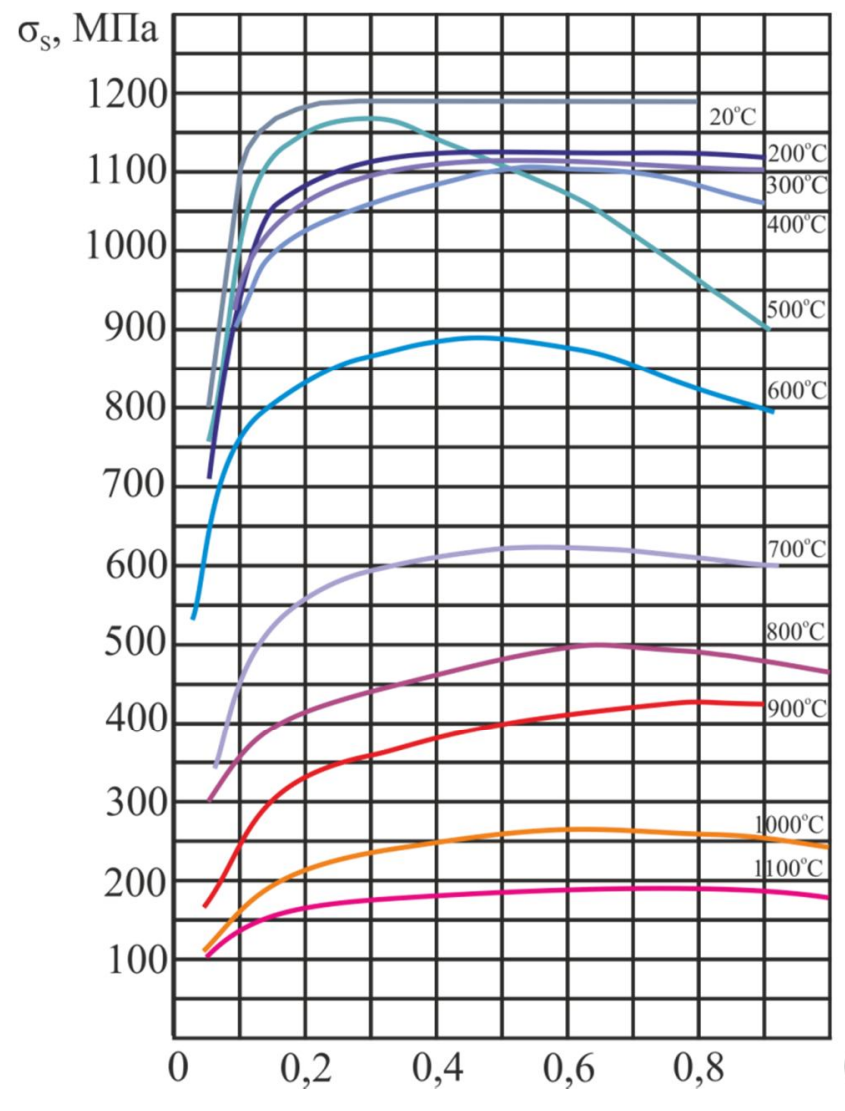

$a$

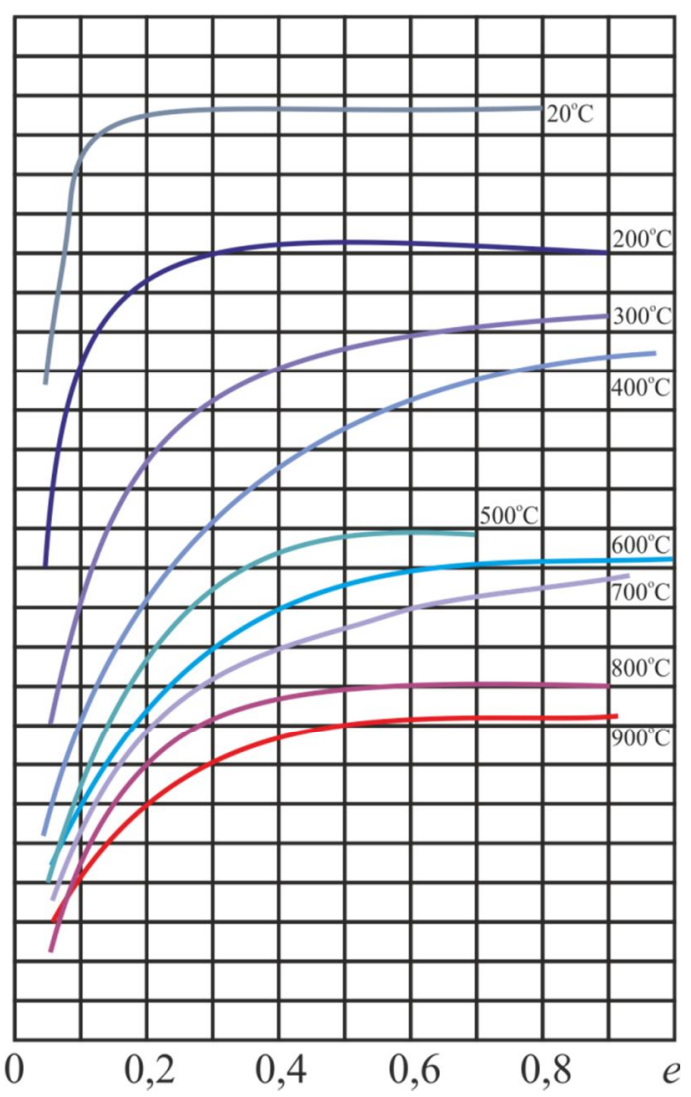

$\sigma$

Рис. 1. Кривые упрочнения стали ЭП679 при осадке со скоростью $1 \mathrm{c}^{-1}$ после прямого нагрева до температуры испытания $t_{\text {исп }}(a)$ и предварительного нагрева до $920{ }^{\circ} \mathrm{C}(\sigma) \mathrm{c}$ охлаждением до $t_{\text {исп }}$

Существенное падение сопротивления деформации в интервале $600-700{ }^{\circ} \mathrm{C}$ связано, вероятно, с протеканием процесса $\alpha \rightarrow \gamma$ - превращения в стали при этих температурах.

Характерной особенностью кривых упрочнения после прямого нагрева является наличие максимума $\sigma_{\mathrm{s}}$, после которого сопротивление деформации снижается благодаря процессам динамического разупрочнения.

Поведение стали после нагрева по режиму $920{ }^{\circ} \mathrm{C}-t_{\text {исп }}$ отличается менее интенсивным упрочнением металла при температурах осадки $300{ }^{\circ} \mathrm{C}$ и выше (см. рис. 1б), а максимальное значении $\sigma_{\mathrm{s}}$ достигается лишь к концу осадки, т.е. при степенях деформации $e$ $=0,8-1,0$. Незначительное динамическое разупрочнение наблюдается при температуре 200 ${ }^{\circ} \mathrm{C}$. Сопротивление деформации при температуре $20{ }^{\circ} \mathrm{C}$ в интервале $e$ от 0,3 до 0,8 практически не меняется.

По указанным кривым упрочнения для степеней деформации $e=0,2$ и $e=0,4$ построена зависимость $\sigma_{\mathrm{s}}$ от температуры испытания (рис. 2), позволяющая более четко проследить изменение $\sigma_{\mathrm{s}}$ при разных режимах нагрева. Из графика следует, что 
предварительный нагрев до $920{ }^{\circ} \mathrm{C}$ с последующим охлаждением металла в печи до $t_{\text {исп }}$ позволяет существенно снизить сопротивление деформации стали ЭП679, особенно в интервале температур деформации $300-700{ }^{\circ} \mathrm{C}$. При этом зависимость $\sigma_{\mathrm{s}}$ от температуры монотонная, скачок уровня $\sigma_{\mathrm{s}}$ при температуре $500{ }^{\circ} \mathrm{C}$ отсутствует. Следует отметить, что зависимость $\sigma_{\mathrm{s}}=f\left(t_{\text {исп }}\right)$ при прямом нагреве до температуры испытания несколько отличается от данных работы [4], полученных для стали близкого состава. Кривая зависимости имеет пик (максимум) при температурах около $500{ }^{\circ} \mathrm{C}$. Наблюдаемые различия могут быть связаны, в частности, с более высоким содержанием титана и никеля, входящих в состав упрочняющих интерметаллидных частиц.

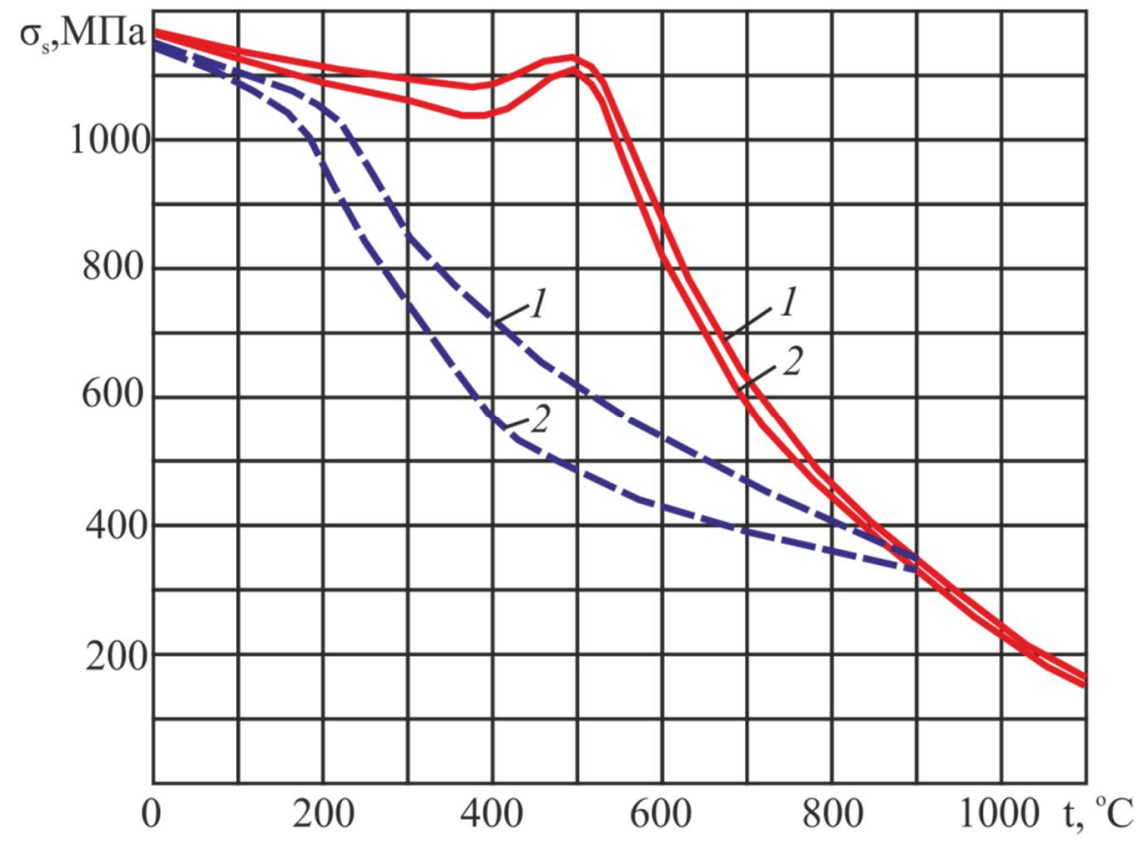

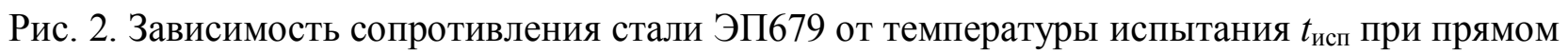
нагреве до $t_{\text {исп }}$ (сплошныле линии) и при нагреве по режиму $920{ }^{\circ} \mathrm{C}-t_{\text {исп }}$ (пунктирныле линии) при степени деформации: $1-e=0,4 ; 2-e=0,2$

Специальной серией опытов проведена оценка влияния режима термообработки (температуры старения) на сопротивление деформации стали. С этой целью закаленные образцы были подвергнуты старению при температурах 400, 500, 600 и $700{ }^{\circ} \mathrm{C}$ в течение 3 ч. Испытания при комнатной температуре показали (рис. 3), что сопротивление деформации стали после старения возрастает в 1,10 - 1,70 раз (в зависимости от температуры старения), при этом максимальная величина $\sigma_{\mathrm{s}}$ имеет место после старения при $500{ }^{\circ} \mathrm{C}$. Отметим, что максимальный уровень $\sigma_{\mathrm{s}}$ тесно коррелирует с уровнем твердости состаренных образцов (см. табл. 2).

Для оценки влияния скорости деформации на упрочнение стали проведены также опыты по осадке образцов со скоростями деформации 10 и $50 \mathrm{c}^{-1}$ после прямого нагрева до

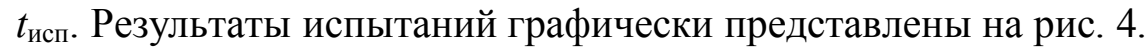




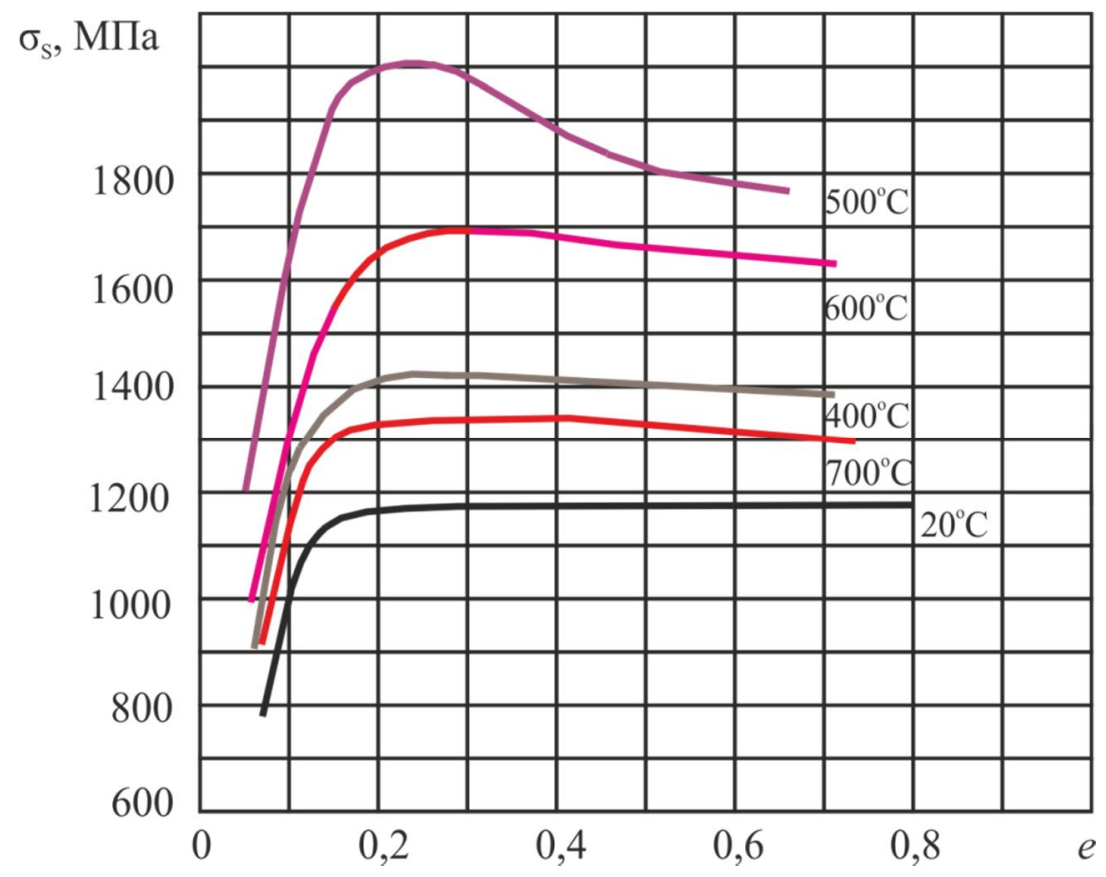

Рис. 3. Зависимость кривых упрочнения стали ЭП679 при комнатной температуре от температуры старения

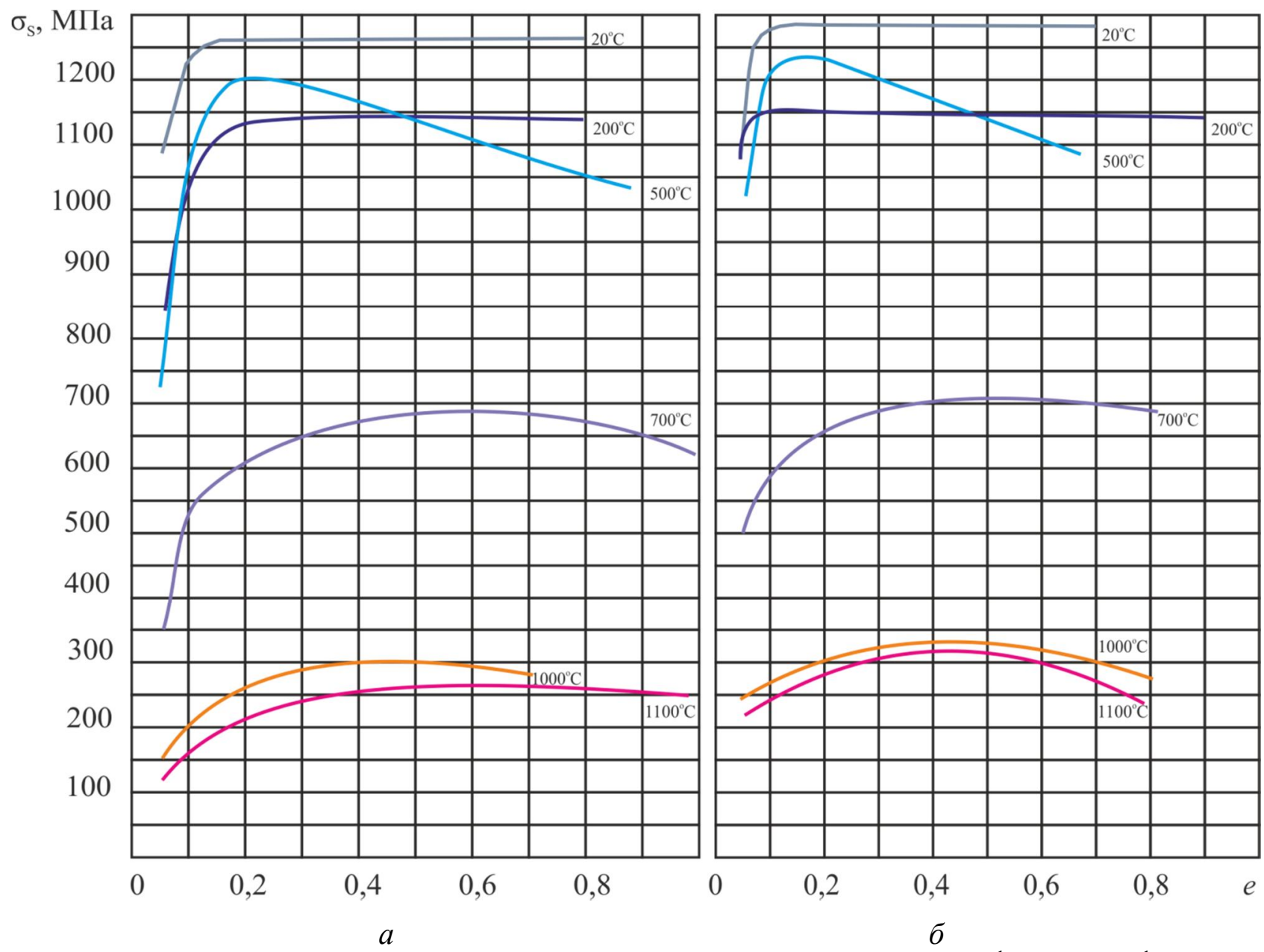

Рис. 4. Кривые упрочнения стали ЭП679 при скоростях деформации $10 \mathrm{c}^{-1}(a)$ и $50 \mathrm{c}^{-1}$ (б) при различных температурах 
Можно отметить, что характер кривых упрочнения с увеличением скорости $\xi$ существенно не меняется. При этом сопротивление деформации возрастает, что наглядно иллюстрируется графиком на рис. 5, построенном по данным рис. $1 a$ и 4 для степени деформации $e=0,4$. Увеличение сопротивления деформации с ростом скорости происходит более интенсивно с повышением температуры испытания, в особенности при температурах горячей деформации. Последнее можно объяснить тем, что при больших скоростях не успевает проходить разупрочнение в результате развития процессов динамической рекристаллизации, а деформационный разогрев принципиально не изменяет реологических свойств стали.

При температуре испытания $700{ }^{\circ} \mathrm{C}$ деформационный разогрев может повысить температуру образца до области горячей деформации, при которой начинается разупрочнение за счет рекристаллизации. В этом случае при повышении скорости деформации рекристаллизация, обусловленная развитием диффузионных процессов, будет запаздывать и, соответственно, способствовать росту значений $\sigma_{\mathrm{s}}$.

В табл. 3 приведены коэффициенты скоростного упрочнения, которые определены как:

- $\mathrm{n}_{1-10}=\sigma_{\mathrm{s}(10)} / \sigma_{\mathrm{s}(1)}$ в интервале изменения скоростей от 1 до $10 \mathrm{c}^{-1}$;

- $\mathrm{n}_{10-50}=\sigma_{\mathrm{s}(50)} / \sigma_{\mathrm{s}(10)}$ в интервале изменения скоростей от 10 до $50 \mathrm{c}^{-1}$;

- $\mathrm{n}_{1-50}=\sigma_{\mathrm{s}(50)} / \sigma_{\mathrm{s}(1)}$ В интервале изменения скоростей от 1 до $50 \mathrm{c}^{-1}$.

Как видно из табл. 3, с увеличением скорости деформации наблюдается тенденция роста коэффициента скоростного упрочнения.

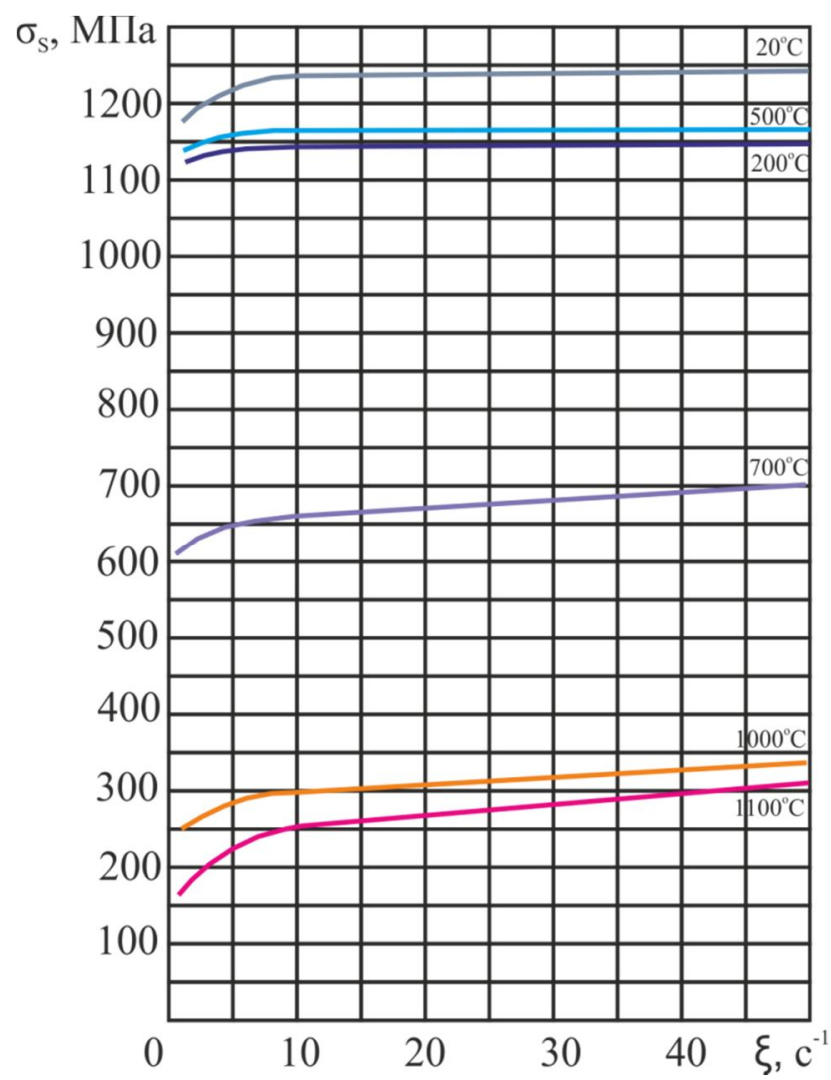

Рис. 5. Зависимость сопротивления деформации стали ЭП679 от скорости деформации $\xi$ при степени деформации $e=0,4$ при различных температурах 
Таблица 3 - Коэффициенты скоростного упрочнения

\begin{tabular}{|l|l|l|l|l|l|l|}
\hline \multirow{2}{*}{$\begin{array}{l}\text { Коэффициент } \\
\text { скоростного упрочнения }\end{array}$} & \multicolumn{7}{|c|}{ Температура испытания, ${ }^{\circ} \mathrm{C}$} \\
\cline { 2 - 8 } & 20 & 200 & 500 & 700 & 1000 & 1100 \\
\hline $\mathrm{n}_{1-10}$ & 1,050 & 1,018 & 1,022 & 1,082 & 1,2 & 1,56 \\
\hline $\mathrm{n}_{10-50}$ & 1,044 & 1,01 & 1,008 & 1,06 & 1,116 & 1,24 \\
\hline $\mathrm{n}_{1-50}$ & 1,098 & 1,026 & 1,031 & 1,147 & 1,34 & 1,937 \\
\hline
\end{tabular}

Следует отметить довольно высокий уровень пластичности стали ЭП679 в закаленном с $920{ }^{\circ} \mathrm{C}$ состоянии. Осадка образцов прошла без трещинообразования за исключением одного образца, который разрушился при степени деформации $e \approx 0,35$ со скоростью $50 \mathrm{c}^{-1}$ после прямого нагрева до $500{ }^{\circ} \mathrm{C}$ в течение 50 мин.

\section{4. Заключение}

1. При прямом нагреве закаленных образцов в интервале температур испытания от 20 до $500{ }^{\circ} \mathrm{C}$ сталь ЭП679 обладает наибольшим сопротивлением деформации $\left(\sigma_{\mathrm{s}}=1000-1200\right.$ МПа). В этом интервале для стали характерно интенсивное упрочнение на начальной стадии деформирования. Наиболее интенсивное упрочнение и высокий уровень сопротивления деформации наблюдаются при температуре $20{ }^{\circ} \mathrm{C}$ и $500{ }^{\circ} \mathrm{C}$. Вместе с тем при температуре $500{ }^{\circ} \mathrm{C}$ по достижению степени деформации $e=0,2-0,3$ происходит интенсивное динамическое разупрочнение металла, которое имеет место при всех изученных скоростях деформации.

2. При выборе режимов обработки стали ЭП679 следует избегать ее деформирования в закаленном состоянии при температурах $20-500{ }^{\circ} \mathrm{C}$ при прямом нагреве, а также после упрочняющего старения при температурах близких к $500{ }^{\circ} \mathrm{C}$ в связи с повышенным сопротивлением деформации и возможностью хрупкого разрушения металла.

3. Сопротивление деформации при температурах $300-700{ }^{\circ} \mathrm{C}$ может быть существенно снижено за счет предварительного нагрева стали до температуры $920{ }^{\circ} \mathrm{C}$ и последующего медленного охлаждения до температуры деформации.

4. Горячую обработку давлением стали ЭП679 рекомендуется проводить при температурах $1000{ }^{\circ} \mathrm{C}$ и выше, что соответствует минимальному уровню сопротивления деформации.

\section{Благодарность}

Работа выполнена в соответствии с планом Фундаментальных научных исследований государственных академий наук на 2013-2020 г. по теме № 01201354598 и при частичной поддержке проекта УрО РАН № 15-15-1-52 (программа УрО РАН «Арктика») и гранта РФФИ № 14-08-31673 мол_а.

\section{Литература}

1. Перкас М. Д., Кардонский В. М. Высокопрочные мартенситно-стареющие стали. М. : Металлургия, 1970. - 224 с.

2. Георгиев М. Н., Симонов Ю. Н. Трещиностойкость железоуглеродистых сплавов. Пермь : Изд-во Перм. нац. исслед. политехн. ун-та, 2013. - 419 с.

3. Влияние условий термопластической обработки на сопротивление деформации, механические свойства и трещиностойкость бескобальтовых мартенситно-стареющих сталей / Б. М. Эфрос, И. П. Конакова, С. В. Гладковский, В. С. Тютенко, Л. В. Лоладзе, Т. П. Заика,

В. Н. Варюхин // Физика и техника высоких давлений. - 1997. - Том. 7, № 4. - С. 5-23. 
4. Деформируемость стали 03Х11Н10М2Т в интервале температур $20-1100{ }^{\circ} \mathrm{C} /$ Ю. Г. Векслер, Н. В. Звигинцев, И. П. Конакова, Г. В. Белова, Г. Н. Сунцев // Известия вузов. Черная металлургия. - 1986. - № 8. - С. 74- 78.

5. Методика исследования сопротивления деформации на пластометрическом комплексе / А. И. Потапов, В. П. Мазунин, Д. А. Двойников, Е. А. Коковихин // Заводская лаборатория. Диагностика материалов. - 2010. - Т.76, № 9. - С.59-63.

6. Терентьев В. В., Бунин И. Ж., Загреев П. В. Влияние температуры старения на комплекс механических свойств мартенситностареющей стали // Материаловедение - 1998. № $1 .-$ C. 40-49.

7. Тарасенко Л. В., Звигинцев Н. В., Титов В. И., Хадыев М. С. Фазовые превращения при длительном старении стали 00Х11М2Т...Т1 // ФММ. - 1987. - Т. 63, вып 4, № 6. С. $768-773$.

8. Термодинамический анализ фазовых равновесий в мартенситностареющих сталях / Н. Г. Шапошников, Б. М. Могутнов, Н. В. Звигинцев, М. С. Хадыев // Термическая обработка, структура и свойства металлов межвуз. сб. - Свердловск : изд-во УПИ им. С.М. Кирова, 1985. - Вып.10., - С. 3-9.

9. Георгиев М. Н., Симонов Ю. Н. Трещиностойкость железоуглеродистых сплавов. Пермь : Изд-во Перм. Нац. Исслед. Политехн. ун-та, 2013. - 419 с.

10. Механические свойства мартенситностареющей стали Н18К8М5Т с остаточным и ревертированным аустенитом / В. П. Вылежнев, А. А. Сухих, В. Г. Брагин, С. А. Коковякина // ФММ. - 1993. - Т.75, вып. 4. - С. 157-165.

11. Влияние структурных превращений на механические свойства и трещиностойкость бескобальтовых мартенситно-стареющих сталей / С. В. Гладковский, Н. В. Звигинцев, А. А. Круглов, Т. А. Дорошкевич, Р. С. Фазлиахметов, В. В. Юровских // ФММ. - 1990. Вып. 2. - С. 106-113. 